\title{
Return Predictability and Labor Market Frictions in a Real Business Cycle Model
}

\author{
November 16, 2008
}

\begin{abstract}
Production-based asset pricing models typically abstract from frictions in the labor market. By construction these models therefore do not match the dynamic behavior of variables such as wages and hours worked. This is potentially a great concern when considering the time-series properties of the value and payout of the firm since about two-thirds of firms' earnings are used to pay labor costs. We show that adding these frictions to a real business cycle model that features endogenous long-run consumption risk, significantly helps the model explain unconditional asset pricing moments and provides a rationale for the relationship between return predictability and fluctuations in labor income.
\end{abstract}




\section{Introduction}

Production-based asset pricing models aim to explain asset prices through the optimal investment behavior of firms given a production function, costs of factor inputs and a stochastic discount factor. In terms of the magnitude of factor costs, labor is the most significant one. In the U.S. economy, labor costs has historically amounted to about two thirds of firms' revenues. Importantly, there is an abundance of evidence that labor markets are not frictionless: Wages are sticky and there are costs to hiring and firing that depend on the state of the economy (see, e.g., Mortensen and Pissarides, 1994, Donaldson and Danthine, 1999, and Hall, 2005). Therefore, wages empirically do not equal the marginal product of labor. Yet production-based asset pricing models typically ignore labor markets altogether or simply assume that labor is paid its marginal product. This is an issue because the costs of labor market frictions can be large. In a rational expectations equilibrium, the optimal investment policy will then be significantly different from the frictionless case. What is more, sluggish adjustment of labor costs gives the firm operating leverage relative to the frictionless case. These facts are important for the dynamic behavior of aggregate dividends and therefore for the asset pricing properties of these models.

In this paper, we consider the effects of labor market frictions in the context of a standard real business cycle model where the representative agent has Epstein-Zin preferences and technology shocks are i.i.d. In this model, long-run consumption risk as in Bansal and Yaron (2004) arises endogenously due to agents' desire to smooth consumption (see Kaltenbrunner and Lochstoer, 2007). It is useful to consider a general equilibrium model with both production and consumption, as opposed to a pure production-based model (as in, e.g., Jermann, 2007), since frictions that affect investment behavior and capital productivity also affect the optimal consumption choice and, therefore, potentially the amount of long-run versus short-run consumption risk in the economy. We show in this paper that introducing labor market frictions that allow the model to match key aggregate labor market moments, significantly improves the model's asset pricing properties.

We depart from the standard model in that labor is pre-determined one period in advance (e.g., Boldrin, Christiano, and Fisher, 2000), wages are sticky (e.g., Hall, 2005), and there are asymmetric adjustment costs to labor, i.e., it is more costly for the firm to fire than to hire. The latter assumption is consistent with new evidence provided in this paper that the sensitivity of wages to changes in labor productivity is higher in expansions than in recessions. These deviations from the standard model allow us to match the fact that wages 
are less volatile than output, that total number of hours worked is pro-cyclical, and that the labor share of output is counter-cyclical. Further, adding these frictions to the model improve on its asset pricing properties. In particular, the two first assumptions make labor costs sluggish. In this case, when a firm experiences a technology shock, the marginal product of labor changes and the firm would therefore like to change its labor stock. Being restricted from doing so effectively creates operating leverage. Dividends become more pro-cyclical and volatile relative to the benchmark case where labor can be adjusted frictionlessly. We show that this channel alone almost triples the volatility of the equity claim, which is much too low in the benchmark model, while the amount of long-run consumption risk is largely unaffected. A levered version of the equity claim in the model has a risk premium of $3.25 \%$, return volatility of $8.9 \%$ and a Sharpe ratio of 0.37 even though the coefficient of relative risk aversion is only 5 . When we increase the risk aversion coefficient to 10 , we match the historical equity risk premium of $6.3 \%$, although the equity Sharpe ratio in this case is too high (0.74).

Asymmetric adjustment costs to capital and, in particular, labor induce time-varying expected excess returns related to fluctuations in labor income. In a recession the firm wants to decrease its labor stock, but faces higher than normal adjustment costs. This leads to higher return volatility and a higher equity premium. Time-variation in the equity premium has been documented in many studies, but importantly Lettau and Ludvigson (2001) and Santos and Veronesi (2006) argue that fluctuations in labor income are important for understanding this predictability. Our model provides a rationale for the link between labor income and expected aggregate stock returns that is missing in production-based models without labor market frictions.

Merz (1995) is an early paper that introduce a labor market matching model into a real business cycle model where the representative agent has power utility preferences. She shows that doing so greatly improves the ability of the model to match key aggregate labor market moments. Hall (2005) argues for introducing sticky wages into the matching model of Mortensen and Pissarides (1994) through time-varying bargaining power between the firm and the worker. Den Haan and Kaltenbrunner (2007) is a recent real business cycle model that features both sticky wages and a matching model. While our specification of labor market frictions is of a more reduced form, we retain the spirit of the frictions in matching models in that employment is predetermined and costly to adjust. Merz and Yashiv (2007) give strong empirical support for the importance of modeling adjustment costs to both capital and labor in order to match the time-series properties of the value of the aggregate stock 
market in a production-based pricing framework. The production-based model with long-run consumption risk is also studied in Kaltenbrunner and Lochstoer (2007) and Croce (2008).

The paper is organized as follows. In section 2, we provide the benchmark model without labor market frictions. While we solve the model numerically, we also provide some approximate closed-form solutions to give intuition for how long-run consumption risk arises endogenously. In section 3, we provide the model with labor market frictions and, show following Merz and Yashiv (2007), how adjustment costs to labor results in a $Q$ with respect to the labor stock, just as the familiar $Q$ with respect to the capital stock arises from capital adjustment costs. Section 4 describes the data and also provide empirical evidence on how the benchmark model fails to match key empirical moments of the aggregate labor market. Section 5 shows the results from the calibrated models. Section 6 argues that the equity claim should not be matched directly with the historical equity risk premium on public equities. Section 7 concludes.

\subsection{Related Literature}

[TO COME]

\section{Benchmark Model}

Our benchmark model is a real business cycle model where identical households derive utility from consumption and profit maximizing firms use capital and labor to produce output. Investment is subject to convex adjustment costs. Labor is exogenous and in fixed supply.

\subsection{Firms}

We model identical firms by a representative firm with a Cobb-Douglas production function, given by

$$
F\left(K_{t}, N_{t}\right)=K_{t}^{\alpha}\left(Z_{t} N_{t}\right)^{1-\alpha}
$$

where $K_{t}$ is the capital stock, $\alpha$ is the capital share of production, $N_{t}$ is hours worked and $Z_{t}$ is an exogenous technological progress given by

$$
\begin{aligned}
\frac{Z_{t+1}}{Z_{t}} & =e^{\varepsilon_{t+1}} \\
\varepsilon_{t} & \sim N\left(\mu, \sigma_{z}\right),
\end{aligned}
$$


where the shocks $\varepsilon_{t}$ are i.i.d.

The capital accumulation equation is given by

$$
K_{t+1}=(1-\delta) K_{t}+I_{t},
$$

where $\delta$ is the capital depreciation rate and $I$ is investment.

The cost of investment is given by

$$
g_{t}=\frac{1}{2} a_{K}\left(\frac{I_{t}}{K_{t}}-\delta\right)^{\eta} K_{t}
$$

where $\eta=2$. We allow $a_{K}$ to be either a constant (symmetric adjustment costs) or countercyclical (asymmetric adjustment costs). The counter-cyclicality is introduced by letting $a_{K}$ take two possible values. When investment is above it's steady-state value, $a_{K}=a_{K}(H)$, otherwise $a_{K}=a_{K}(L)$.

The amount of labor available to the firm is fixed. The wage rate is $W_{t}$ and is given by the marginal product of labor. To see this note that the firm chooses labor and capital to maximize expected discounted profits, given by

$$
E_{0} \sum_{t=0}^{\infty} M_{0, t} D_{t}
$$

subject to the capital accumulation equation (4), where $M_{0, t}$ is the stochastic discount factor used to find the date- 0 price of date- $t$ cash flows and $D_{t}=F\left(K_{t}, N_{t}\right)-W_{t} N_{t}-I_{t}-g_{t}$ is the profit or dividend. Therefore, the firm's value function is

$$
V_{t}=\max _{I_{t}, N_{t}} F\left(K_{t}, N_{t}\right)-W_{t} N_{t}-I_{t}-g_{t}+E_{t}\left[M_{t, t+1} V_{t+1}\right]
$$

subject to (4). It then follows that the firm's first order conditions are summarized by

$$
W_{t}=F_{K}\left(K_{t}, N_{t}\right)=(1-\alpha) \frac{F\left(K_{t}, N_{t}\right)}{N_{t}},
$$

and

$$
E_{t}\left[M_{t, t+1} R_{t+1}^{I}\right]=1,
$$


where the firm's return on investment is given by

$$
R_{t+1}^{I}=\frac{\alpha F_{K}\left(K_{t+1}, N_{t+1}\right)-g_{K_{t+1}}+Q_{t+1}^{K}(1-\delta)}{Q_{t}^{K}}
$$

and marginal- $q$, the shadow price of capital is given by

$$
Q_{t}^{K}=1+g_{I_{t}}
$$

Note that when there are no adjustment costs, marginal- $q$ is unity.

\subsection{Households}

Identical households are modeled by a infinitely-lived representative agent who derives utility from consumption and has Epstein-Zin preferences (see Kreps and Porteus (1978), Epstein and Zin (1989) and Weil (1989)). The date-t utility of the agent, $U_{t}$, satisfies

$$
U_{t}=f\left(C_{t}, \mu_{t}\left[U_{t+1}\right]\right)
$$

where $f(x, y)$ is the Kreps-Porteus intertemporal aggregator, given by

$$
f(x, y)=\left((1-\beta) x^{\frac{1-\gamma}{\theta}}+\beta y^{\frac{1-\gamma}{\theta}}\right)^{\frac{\theta}{1-\gamma}}
$$

$\beta$ is the rate of time preference, $\gamma$, is relative risk aversion and $\theta=\frac{1-\gamma}{1-1 / \psi}$, where $\psi$ is the elasticity of intertemporal substitution (EIS). The date- $t$ certainty equivalent operator, $\mu_{t}[\cdot]$, is given by

$$
\mu_{t}\left[x_{t+1}\right]=E_{t}\left[x_{t+1}^{1-\gamma}\right]^{\frac{1}{1-\gamma}}
$$

where $x_{t+1}$ is a date- $t$ random variable, which is realized at date $t+1$.

Epstein-Zin preferences make it possible to separate relative risk aversion from EIS. To understand why this separation is desirable from a microeconomic foundational perspective, observe that relative risk aversion measures aversion to atemporal risk and thus governs the agent's preferences across states. In contrast, EIS is well-defined concept under certainty and measures the agent's willingness to postpone consumption over time. Thus, the EIS governs the agent's preferences over time. With standard power utility, this two different aspects of the agent's preferences are tied together, so that relative risk aversion is the reciprocal of the EIS, i.e. $\gamma=1 / \psi$. 
The parameters $\gamma$ and $\psi$ also govern the agent's preference for the timing of the resolution of intertemporal uncertainty. When $\gamma>1 / \psi$, the agent prefers to resolve intertemporal uncertainty sooner rather than later, that is, she prefers information to be revealed earlier rather than later, even if she does not use this information in her decisions (see Lazrak (2004)). When $\gamma=1 / \psi$, the power utility case, the agent is indifferent about whether intertemporal uncertainty is resolved sooner or later and when $\gamma<1 / \psi$, she prefers later resolution. In our model, we assume that $\gamma>1 / \psi$.

Households can either consume their wealth or save it by investing in a locally risk-free bond or purchasing shares in the claim to consumption, $C=Y-I-g=D+W N$. Hence, the return on the representative agent's portfolio is

$$
R_{p, t+1}=\pi_{t} \frac{P_{C, t+1}+C_{t+1}}{P_{C, t}}+\left(1-\pi_{t}\right) R_{f, t+1},
$$

where $\pi_{t}$ is the proportion of her savings invested in the claim to consumption, $P_{C}$ is the price of the consumption claim and $R_{f, t+1}$ is the risk-free return. The representative agent's value function, $J$, is given by

$$
J_{t}=\max _{\bar{C}_{t}, \pi_{t}} f\left(\bar{C}_{t}, \mu_{t}\left[J_{t+1}\right]\right)
$$

subject to the budget constraint

$$
A_{t+1}=\left(A_{t}-\bar{C}_{t}\right) R_{p, t+1}
$$

where $\bar{C}$ is the consumption control, as opposed to $C$, which is result of the firm's investment decision. Of course, in equilibrium, $\bar{C}=C$.

The household's first order conditions, give us the standard Lucas Euler equation

$$
E_{t}\left[M_{t+1} R_{t+1}\right]
$$

where $R$ is an asset return. For example, $R=R_{C}$, where

$$
R_{C, t+1}=\frac{P_{C, t+1}+C_{t+1}}{P_{C, t}}
$$


and the stochastic discount factor, $M_{t+1}=M_{t, t+1}$, is given by

$$
M_{t, t+1} \equiv \beta\left(\frac{C_{t+1}}{C_{t}}\right)^{-\frac{1}{\psi}}\left(\frac{J_{t+1}}{\mu_{t}\left[J_{t+1}\right]}\right)^{-(\gamma-1 / \psi)}
$$

or equivalently

$$
M_{t, t+1} \equiv \beta^{\theta}\left(\frac{C_{t+1}}{C_{t}}\right)^{-\frac{\theta}{\psi}} R_{A, t+1}^{\theta-1}
$$

where $R_{A, t+1}$ is the return on aggregate wealth. Thus,

$$
R_{A, t+1}=\frac{A_{t+1}}{A_{t}-C_{t}}
$$

where $A_{t}$ is cum-dividend aggregate wealth. Note that in equilibrium, market clearing implies that $\pi=1$, so the above equation is consistent (in equilibrium) with (17).

The stochastic discount factor above shows that when valuing assets, an agent with Epstein-Zin preferences cares about the path of future consumption, not just the current rate of consumption growth. To see this note that the value function captures the utility of future consumption and that the value function normalized by its certainty equivalent appears in the stochastic discount factor. Thus risks at different dates are not valued separately. In contrast, for the special case of power utility, the stochastic discount factor no longer depends on the normalized value function, and thus shocks to the path of future consumption growth are not priced - only current consumption growth matters.

Using a log-linear approximation, we can show that the risk premium on an asset is given by

$$
E_{t}\left[R_{t+1}\right]-R_{f, t+1} \approx-\frac{1}{\psi} \operatorname{Cov}_{t}\left(R_{t+1}, \Delta c_{t+1}\right)+(\gamma-1 / \psi) \operatorname{Cov}_{t}\left(R_{t+1}, \ln J_{t+1}\right)
$$

where $c=\ln C$ and $\Delta c_{t+1}=c_{t+1}-c_{t}$. The above expression shows that the risk premium is high when either returns covary strongly (and negatively) with consumption growth (the standard term which also appears when the agent has power utility) or returns covary strongly with the value function (an additional term which is present only when agent's have a preference for the timing of the resolution of intertemporal risk, i.e. $\gamma \neq 1 / \psi$ ).

\subsection{Central Planner's Solution}

The equilibrium of the decentralized economy described above is the same as the equilibrium

chosen by a central planner, who has Epstein-Zin-Weil preferences. We use this approach to 
compute equilibrium prices and quantities.

Once we have solved for consumption and labor income, $L=W N$, we can value these cash flows using the stochastic discount factor. Hence, we obtain the price of the claim to aggregate consumption, $P_{C}$, given by

$$
P_{C, t}=E_{t}\left[M_{t, t+1}\left(C_{t+1}+P_{C, t+1}\right)\right],
$$

the price of the claim to labor income, $P_{L}$, given by

$$
P_{L, t}=E_{t}\left[M_{t, t+1}\left(W_{t+1} N_{t+1}+P_{L, t+1}\right)\right] .
$$

Since dividends are given by $D_{t}=C_{t}-W_{t} N_{t}$, the price of the claim to dividends is $P_{D, t}=$ $P_{C, t}-P_{L, t}$. Note that the price of the claim to dividends equals the maximized expected present value of the firm's discounted profits in (6).

We can also find the risk-free state, $R_{f, t+1}$, via the stochastic discount factor since

$$
R_{f, t+1}=\frac{1}{E_{t}\left[M_{t, t+1}\right]} .
$$

\subsection{A Closed-Form Solution}

For the special case of $g=0$, i.e. zero adjustment costs we can obtain an approximate closed form solution to the continuous-time version of the central planner's problem. This closed-form approach has the advantage that we can derive the dynamics of the capital stock, consumption growth and labor income.

We obtain a closed-form solution by solving the Hamilton-Jacobi-Bellman equation via a perturbation expansion around the case of $\alpha=1$. The following proposition provides first order expressions for the representative agent's value function, $J$, and optimal consumption, $C$, in terms of capital, $K$, and exogenous parameters. While not as accurate as the numerical solution we use in subsequent sections, the closed form nature of the approximate solutions provides some useful insights.

Proposition 1 The representative agent's value function, $J$, and optimal consumption, $C$, 
are given by

$$
\begin{aligned}
J & =\frac{\left[\left(\frac{\varepsilon^{\psi}}{c_{0}}\right)^{\frac{1}{\psi-1}} e^{\frac{(1-\alpha)\left(\mu_{\delta}+c_{0}\right)}{c_{0}^{2}}}\left(\frac{K}{N Z}\right)^{-\frac{1-\alpha}{c}} K\right]^{1-\gamma}}{1-\gamma}, \\
C & =E\left(\frac{K}{N Z}\right)^{\frac{(1-\alpha)(\psi-1)}{c_{0}}} K,
\end{aligned}
$$

where

$$
E=c_{0}\left(1-\frac{1-\alpha}{c_{0}}\right)^{-\psi} e^{-\frac{(1-\alpha)(\psi-1)}{c_{0}^{2}}\left(\mu_{\delta}+c_{0}\right)},
$$

$\varepsilon=-\ln \beta, \mu_{\delta}=\mu-\frac{1}{2} \sigma^{2}-(1-\delta)$ and $c_{0}=(1-\delta)(1-\psi)+\varepsilon \psi$ is the optimal consumptioncapital ratio when $\alpha=1$.

From the above proposition we can see that when $\psi=1$, the optimal consumption-capital ratio is constant and since capital growth is locally risk-free, so is consumption growth. This is no longer the case when $\psi \neq 1$ : the elasticity of consumption with respect to technological progress is

$$
\frac{\partial \ln C}{\partial \ln Z}=-\frac{(1-\alpha)(\psi-1)}{c_{0}}+O\left((\alpha-1)^{2}\right),
$$

which is non-zero because income and substitution effects no longer offset each other.

From Proposition 1, we can derive first order expressions for the evolution of capital and consumption, investment, labor income and dividends.

Proposition 2 The joint dynamics of $\log$ capital, $k=\ln K$, and the log of technology, $z=\ln Z$, are given by

$$
\begin{aligned}
d k & =(A-B(k-z-n)) d t \\
d z & =\left(\mu-\frac{1}{2} \sigma^{2}\right) d t+\sigma d w,
\end{aligned}
$$

where $w$ is a standard Brownian motion, $n=\ln N$, and

$$
\begin{aligned}
& A=1-\delta-E \\
& B=(1-\alpha)\left(1+E \frac{(\psi-1)}{c_{0}}\right) .
\end{aligned}
$$


The dynamics of $\log$ consumption, $c=\ln C$, are given by

$$
d c=\left(A_{c}-B(c-z-n)\right) d t+\sigma_{c} d w
$$

where

$$
\begin{aligned}
& A_{c}=\left(\frac{(1-\alpha)(\psi-1)}{c_{0}}+1\right) A+\ln E, \\
& \sigma_{c}=-\frac{(1-\alpha)(\psi-1)}{c_{0}} \sigma .
\end{aligned}
$$

The dynamics of log labor income, $l=\ln W N$, are given by

$$
d l=\left(A_{l}-B(l-z-n)\right) d t+\sigma_{l} d w
$$

where

$$
\begin{aligned}
& A_{l}=\alpha A+\ln (1-\alpha)-(1-\alpha)\left(\mu-\frac{1}{2} \sigma^{2}\right) \\
& \sigma_{l}=(1-\alpha) \sigma .
\end{aligned}
$$

The dynamics of $\log$ dividends, $\zeta=\ln D$, are given by

$$
\begin{aligned}
d \zeta= & \frac{1}{\omega_{D}}\left(A_{c}-B(c-z-n)+\frac{1}{2} \sigma_{c}^{2}\right) d t-\left(\frac{1}{\omega_{D}}-1\right)\left(A_{l}-B(l-z-n)+\frac{1}{2} \sigma_{l}^{2}\right) d t \\
& +\left(\frac{1}{\omega_{D}} \sigma_{c}-\left(\frac{1}{\omega_{D}}-1\right) \sigma_{l}\right) d w
\end{aligned}
$$

where $\omega_{D}=\frac{D}{C}$ is the ratio of dividends to consumption.

The above proposition shows that log-capital converges exponentially to a steady-state value of $\frac{A}{B}+n+z$ at the rate $B$.

More importantly, log-consumption is mean-reverting, with long-run mean $\frac{A}{B}+n+z$ and a rate of mean reversion of $B$. This implies that there is long-run risk in consumption growth, which arises endogenously as a consequence of the agent's optimal behaviour, even though the exogenous technology shock is i.i.d. This is an analytical confirmation of the numerical results in Kaltenbrunner and Lochstoer (2007). We can see that log-consumption is mean reverting unless $\alpha=1$, i.e. the technology is linear $K$. When $\psi=1, \log$ consumption is mean reverting and locally risk-free, so the expected growth rate of consumption is subject 
to long-run risk.

Log labor income is also subject to long-run risk, but in contrast with log consumption is still volatile when $\psi=1$.

The dynamics of log dividends are more complex that those of log consumption or log labor income, although it is still apparent that expected dividend growth is subject to long run risk.

We can obtain the risk-free rate and market price of consumption risk from the stochastic discount factor, $M$. It is a standard result that the stochastic discount factor, $M$, is given by

$$
\frac{d M}{M}=-r d t-\Theta d z
$$

where, $r$, is the locally risk-free rate and, $\Theta$, is the price of consumption risk. To leading order, we can show that

$$
\begin{aligned}
r & =r_{0}+r_{1}(c-z-n), \\
\Theta & =\frac{(\gamma-1)(1-\alpha)}{c_{0}}
\end{aligned}
$$

where $r_{0}$ and $r_{1}$ are constants given in the Appendix.

Thus we can see that increasing risk aversion increases the price of consumption risk and decreasing the capital share has the same effect, because it reduces the ability of the central to control the growth rate of capital via investment. Recall that $c_{0}=(1-\delta)(1-\psi)+\varepsilon \psi$ is the consumption-capital ratio when $\alpha=1$. Therefore $c_{0}$ is decreasing in $\psi$ (assuming $\delta+\epsilon<1$ ), since the agent consumes less of the capital stock and saves more as her aversion to non-smooth consumption declines. Consequently, the market price of risk increases with the EIS, as found numerically in Kaltenbrunner and Lochstoer (2007).

The risk-free rate is linear in log-consumption and the log of technological progress, so the term structure implied by our model will be affine.

We can in principle compute asset prices in closed-form. The resulting expressions for risk premia are zero to first order $\alpha-1$. That implies that in the benchmark model without adjustment costs risk premia are small. We know from Kaltenbrunner and Lochstoer (2007) that this is true even with adjustment costs. 


\section{Full Model}

In the full model households behave in exactly the same way as in the benchmark model. The key differences lie in the behavior of firms.

\subsection{Firms}

We now assume that the labor available to firms follows an accumulation equation and is subject to adjustment costs. Hence,

$$
N_{t+1}=N_{t}+H_{t}
$$

where $H$ is the number of new hires. The capital accumulation equation is now given by

$$
K_{t+1}=(1-\delta) K_{t}-I_{t}
$$

Both labor and investment are subject to adjustment costs, the sum of which is given by

$$
g_{t}=\frac{a_{N}}{2}\left(\frac{H_{t}}{N_{t}}\right)^{2} K_{t}+\frac{a_{K}}{2}\left(\frac{I_{t}}{K_{t}}-\delta\right)^{2} K_{t}
$$

We allow for both symmetric adjustments costs where $a_{N}$ and $a_{K}$ are constants and asymmetric adjustment costs, where $a_{N}$ and $a_{K}$ take higher values when the firm fires workers $\left(H_{t}<0\right)$ or disinvest relative to the steady state $\left(\frac{I_{t}}{K_{t}}<\delta\right)$. In the next section, we will provide new empirical evidence that supports the assumption of higher adjustment costs to labor when the firm scales down its labor stock.

Adjustment costs reduce consumption, and so

$$
C_{t}=Y_{t}-I_{t}-g_{t}
$$

The firm's problem is to maximize expected discounted profits

$$
\max _{\left\{I_{t}, K_{t+1}, H_{t}, N_{t+1}\right\}_{t=0}^{\infty}} E_{0}\left[\sum_{t=0}^{\infty} M_{0, t}\left(Y_{t}-W_{t} N_{t}-I_{t}-g_{t}\right)\right]
$$

subject to the labor and capital accumulation equations, (45) and (46), respectively.

We can derive the first order conditions of the firm in the same way as for the benchmark 
model. The return on hiring is given by

$$
R_{H, t+1}=\frac{(1-\alpha) \frac{Y_{t}}{N_{t}}-g_{N_{t+1}}-W_{t+1}+Q_{t+1}^{N}}{Q_{t}^{N}}
$$

where $Q^{N}$ is the shadow price of hiring, given by

$$
Q_{t}^{N}=g_{H_{t}}
$$

and

$$
E_{t}\left[M_{t+1} R_{H, t+1}\right]=1 \text {. }
$$

The first order conditions associated with capital and investment remain unchanged.

\subsubsection{Determination of Wages}

We assume that wages are given exogenously. One specification we use is that wages are predetermined. Hence, (52) implies that

$$
E_{t}\left[M_{t+1}\right] W_{t+1}=E_{t}\left[M_{t+1}\left\{(1-\alpha) K_{t+1}^{\alpha} N_{t+1}^{-\alpha}-g_{N_{t+1}}+Q_{t+1}^{N}\right\}\right]-Q_{t}^{N}
$$

which is equivalent to

$$
\frac{W_{t+1}}{R_{f, t+1}}=E_{t}\left[M_{t+1}\left\{(1-\alpha) K_{t+1}^{\alpha} N_{t+1}^{-\alpha}-g_{N_{t+1}}+Q_{t+1}^{N}\right\}\right]-Q_{t}^{N}
$$

We can gain some intuition for the above expression by noting that if there are no adjustment costs it reduces to

$$
\frac{W_{t+1}}{R_{f, t}}=E_{t}\left[M_{t+1}(1-\alpha) \frac{F\left(K_{t+1}, N_{t+1}\right)}{N_{t+1}}\right] .
$$

which means that he present value of next period's wages equals the expected market value of the marginal product of labor.

The other specification we use is that wages are sticky and given by

$$
W_{t}=(1-\alpha) \overline{W Y}_{t}^{\eta} K_{t}^{1-\eta}
$$

where

$$
\bar{Y}_{t}=K_{t}^{\alpha} Z_{t}^{1-\alpha}
$$


The parameter $\eta$ governs the level of stickiness. A lower $\eta$ means more stickiness. It follows from the above two equations that wages are given by

$$
W_{t}=(1-\alpha) \bar{W}\left(K_{t}^{\alpha} Z_{t}^{1-\alpha}\right)^{\eta} K_{t}^{1-\eta}=\bar{w} K_{t}^{\eta \alpha+1-\eta} Z_{t}^{(1-\alpha) \eta},
$$

which makes it easy to see that when $\eta$ is smaller, wages load less heavily on the current technology shock and are hence more sticky.

\subsection{Asset Prices and the New Q}

We restate the following proposition based on Merz and Yashiv (2005).

Proposition 3 The expected present value of the firm's discounted profits, i.e. dividends is given by

$$
P_{D, t}=Q_{t}^{K} K_{t+1}+Q_{t}^{N} N_{t+1},
$$

where $Q_{t}^{K}$ is marginal-q, the shadow price of capital and $Q_{t}^{N}$ is the shadow price of employment.

The above proposition tells us that the value of the firm does not just depend on the shadow price of capital and it's level, but also on the shadow price of employment and it's level. Note that while the shadow price of capital is one when capital adjustment is costless, the shadow price of employment is zero when labor adjusts costlessly. The reason is that while investment affects the growth rate of capital directly, hiring does not.

The new term, $Q_{t}^{N} N_{t+1}$, in the firm's value will lead to an additional component in the risk premium. Furthermore, combined with asymmetric adjustment costs for labor the extra term provides a channel for linking time variation in labor with time variation in returns and thus providing some underpinnings for the results on stock return predictability and labor income in Santos and Veronesi (2004).

\section{Data}

The data used in this paper are taken from the Bureau of Economic Analysis and the Bureau of Labor Statistics. We use the long annual sample from 1929 - 2006 when available for computing aggregate quantity moments. Otherwise, we use the quarterly data available 
from 1952 to 2006. All variables have been deflated using the Personal Consumption Expenditures deflator. The model does not have a government sector or durable consumption, although these are quantitatively significant fractions of Gross Domestic Product (GDP). In the post-WWII sample, government consumption and expenditures has been on average $20 \%$ of GDP, while durable consumption has been on average $8.5 \%$ of GDP and $13 \%$ of Personal Consumption Expenditures (PCE). Thus, the model does not account for $28.5 \%$ of the total output. This facts complicates calibration of the model as it is not altogether clear which moments to match. In our calibration of the model, we use the variables as defined below to compute sample moments.

\section{Output}

The data as given by NIPA allows for a relatively clear separation of government consumption and investment from private consumption and investment. Therefore, it seems pertinent and is standard to exclude the government sector from the definition of the output of the economy for the purposes of calibrating this model.

\section{Investment}

Since the model does not explicitly feature durable goods, we follow Cooley and Prescott (1995) and define durable consumption expenditures plus gross private investments as aggregate investments.

\section{Consumption}

We define aggregate consumption as nondurable plus services consumption expenditures. Strictly speaking we should also impute the service flow from the stock of durables as a part of aggregate consumption. However, in the calibration we ignore this component so the consumption data is consistent with what has been used in the long-run risk asset pricing literature.

\section{Asset Pricing Moments}

The asset pricing moments are taken from Bansal and Yaron (2004). We use these moments so the results are easy to compare to the findings from this paper. We will also report some moments for the return to the aggregate wealth portfolio which are taken from Lustig, Van Nieuwerburgh, and Verdelhan (2008). 


\subsection{Aggregate Labor Market Moments}

The data in this section is taken from the Bureau of Labor Statistics' releases for the nonfarm business sector, as is standard in the literature. The available data is from 1947Q1 - 2007Q4. The real wage rate is defined as real total compensation divided by total hours worked. Note that this measure of labor input includes variations in the level of employment as the total hours worked will increase if more workers are employed (holding the average number of hours worked constant).

First note that labor productivity is defined as output over number of hours and can therefore be related to the marginal product of labor in the frictionless model as follows:

$$
\frac{Y_{t}}{N_{t}}=\frac{M P L_{t}}{1-\alpha}=Z_{t}^{1-\alpha} K_{t}^{\alpha} N_{t}^{-\alpha}
$$

In the case of no adjustment costs to labor (and no boundary solution in terms of available labor supply), we have that in equilibrium

$$
W_{t}=M P L_{t}
$$

That is, the firm demands labor, $N_{t}$, until the marginal product of labor equals the given wage rate. Further, this relation implies that the labor share is constant:

$$
\frac{W_{t} N_{t}}{Y_{t}}=1-\alpha
$$

Both of these conditions are strongly violated in the data, as Table 1 shows. The volatility of wages is less than half the volatility of output and also less than the volatility of labor productivity. Hours worked is almost as volatile as output and the labor share is half as volatile as output - i.e., it is far from constant. The lower part of the table shows the historical correlations between these variables. Hours worked, are strongly pro-cyclical while wages and labor productivity are less so. Thus, wages appear to be sticky relative to the predictions of the standard model. The labor share is counter-cyclical, implying that the capital share is pro-cyclical. This is important, as it turns out, for the volatility of the equity claim.

We draw two important conclusions from this data. First, wages are sticky in that they are not highly correlated with and less volatile than output. Second, there is a wedge between labor productivity and wages that is unexplained by the standard model. Amending 


\section{Table 1 - Labor Market Statistics}

Table 1: All data is logged and HP-filtered with a quarterly smoothing parameter of 1600 . The sample is 1947Q1 - 2007Q4 (244 observations).

\section{Labor Market Relative Volatilities}

\begin{tabular}{clc}
\hline Moment & \multicolumn{1}{c}{ Description } & Value \\
\hline$\sigma(y)$ & Volatility of quarterly, HP-filtered output & $2.17 \%$ \\
$\sigma(w) / \sigma(y)$ & Relative volatility of wages & 0.41 \\
$\sigma(m p l) / \sigma(y)$ & Relative volatility of labor productivity & 0.50 \\
$\sigma(h) / \sigma(y)$ & Relative volatility of total hours employed & 0.84 \\
$\sigma(l s) / \sigma(y)$ & Relative volatility of the labor share & 0.50 \\
\hline
\end{tabular}

\section{Labor Market Correlations}

\begin{tabular}{cccccc}
\hline Variable & \multicolumn{5}{c}{ Correlation Matrix } \\
\hline Output & 1 & & & & \\
Wages & 0.31 & 1 & & & \\
Labor Productivity & 0.55 & 0.42 & 1 & & \\
Hours & 0.87 & 0.12 & 0.05 & 1 & \\
Labor Share & -0.29 & 0.40 & -0.66 & 0.05 & 1 \\
\hline
\end{tabular}


the model so it can explain these features of the data will also enable us to explain the high volatility and pro-cyclicality of hours worked and the counter-cyclical labor share. Figure 1 shows the different HP-filtered labor series relative to output (dashed, red line).

Figure 1 - The Cyclical Behavior of Aggregate Labor Market Variables
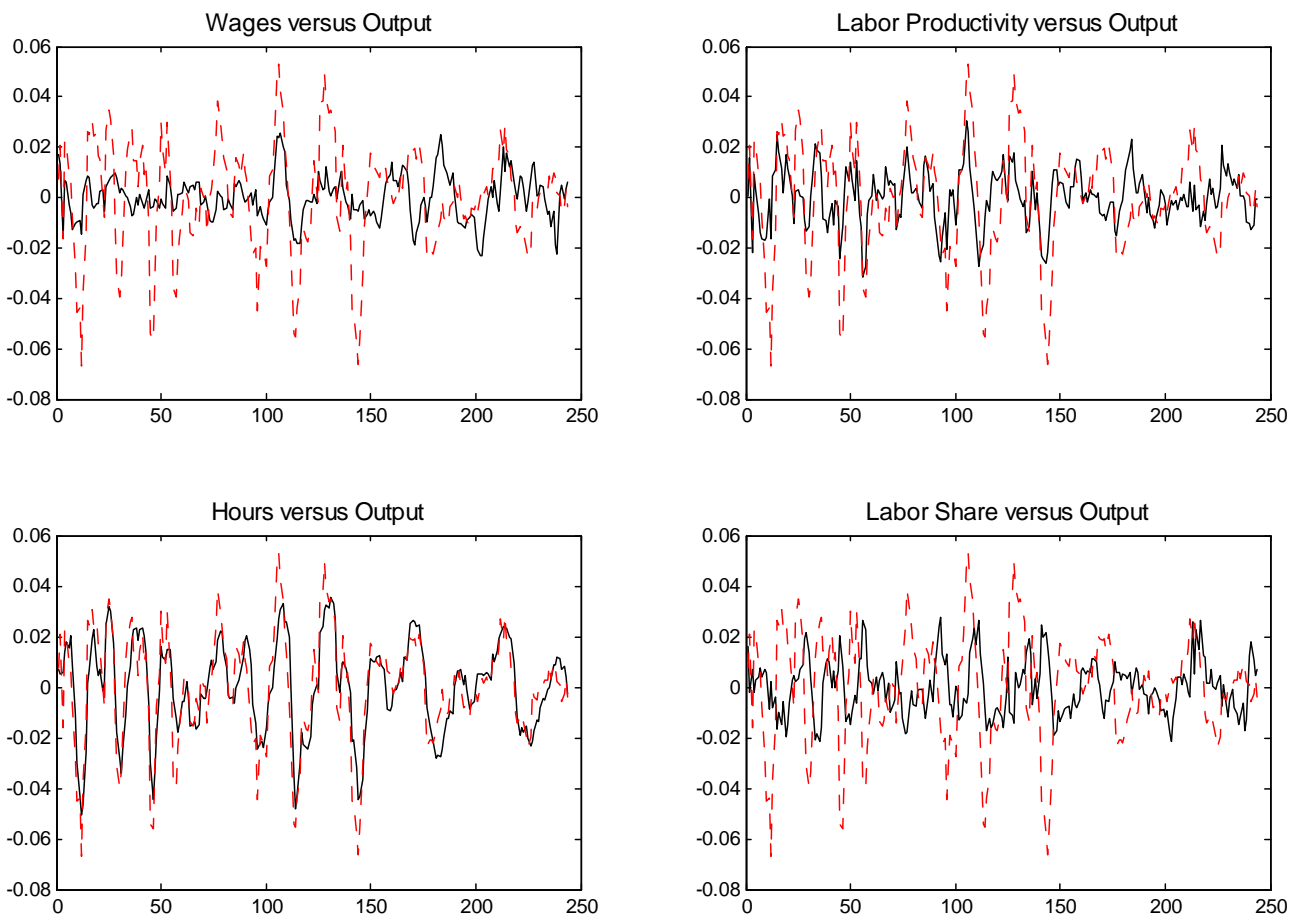

Figure 1: The Cyclical Behavior of Aggregate Labor Market Variables. The figure shows the cyclical component of wages, labor productivity, hours, and the labor share (black solid line) versus the cyclical component of output (red, dashed line).

\section{Sticky Wages and Labor Adjustment Costs}

There is a large literature in labor economics that in part seek to explain why in the data the marginal product of labor is different from the wage rate. In particular, there are important frictions to allocating labor in the economy and this feature has been formalized in, for instance, matching models (see Mortensen and Pissarides (2000) for a review). These models explicitly consider unemployment, matching between firms and workers and wage determination. In this paper, we will take a more reduced form approach and simply specify adjustment costs to change the labor employed by the firm. In addition, we will specify an 


\section{Table 2 - Wage Regression}

Table 2: All data is logged and HP-filtered with a quarterly smoothing parameter of 1600 . w denotes the wage rate and mpl denotes labor productivity. White $t$-statistics are reported in parentheses. One, two, or three asterices denote significance at the ten, five, or one percent level or better, respectively.

\begin{tabular}{ccccc}
\multicolumn{4}{c}{$w_{t}^{H P}=\beta_{0}+\left(\beta_{1}+\beta_{2} m p l_{t}^{H P}\right) \times m p l_{t}^{H P}+\varepsilon_{t}$} \\
\hline & $\beta_{0}$ & $\beta_{1}$ & $\beta_{2}$ & $R^{2}$ \\
\cline { 2 - 5 } Coefficients & -0.0009 & 0.3614 & 7.6690 & $19.9 \%$ \\
$t-$ statistics & $(-1.4289)$ & $\left(8.2401^{* * *}\right)$ & $\left(3.0741^{* * *}\right)$ & \\
\hline
\end{tabular}

exogenous wage rule. These features allow us to calibrate the model to match the broad aggregate labor market statistics given above.

However, first we dig a little deeper on the relationship between wages and relative to labor productivity, which is important for specifying the labor adjustment costs and wage rule. In particular, we run the regression:

$$
w_{t}^{H P}=\beta_{0}+\left(\beta_{1}+\beta_{2} m p l_{t}^{H P}\right) \times m p l_{t}^{H P}+\varepsilon_{t},
$$

in order to determine the nature of the deviations between marginal product of labor and wages. We include a time-varying regression coefficient (really, just the squared value of MPL) to uncover any time-variation in this relation related to the business cycle. Table 2 shows that the wage rate is positively related to labor productivity, as we would expect, but more so in expansions (when labor productivity is high). The fact that wages are more sensitive to labor productivity in expansions than in recessions indicates that wages are stickier or adjustment costs higher (or both) in recessions than in expansions. This result is consistent with a world with higher adjustment costs for firing than hiring and/or a world where it is harder to adjust wages downwards. Figure 2 shows that this time-varying sensitivity $\left(\beta_{t} \equiv \beta_{2}+\beta_{3} m p l_{t}^{H P}\right)$ is economically significant, ranging between 0.15 and 0.55 .

In sum, there is substantial evidence of labor market frictions, which has been the subject of much earlier research also within the real business cycle literature (see, e.g., King and Rebelo (2000) and Danthine and Donaldson (1999)). We document a new finding, to our 
Figure 2 - The Time-Varying Sensitivity of Wages to Labor Productivity

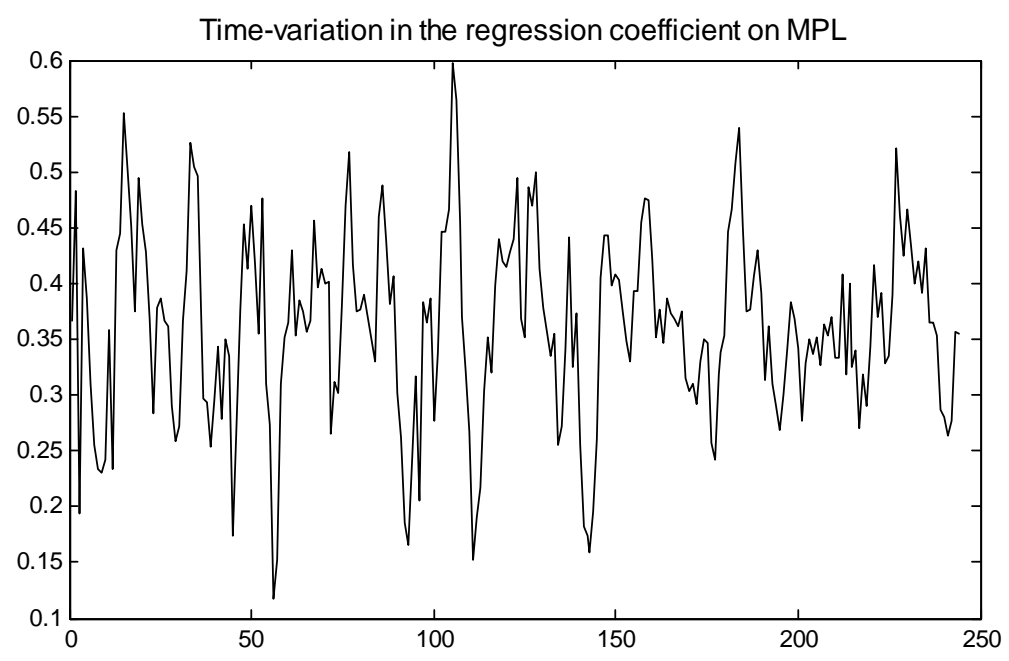

Figure 2: The Time-Varying Sensitivity of Wages to Labor Productivity. The figure shows the implied conditional beta of the cyclical component of wages with respect to the cyclical component of labor productivity, $\beta_{t}=\beta_{1}+\beta_{2} m p l_{t}$, where $\beta_{1}$ and $\beta_{2}$ are from the regression $w_{t}=\beta_{0}+\beta_{1} m p l_{t}+\beta_{2} m p l_{t}^{2}+\varepsilon_{t}$.

knowledge, that wages are less sensitive to fluctuations in labor productivity in recessions. We include this feature in our model and show that it helps to explain empirical evidence on excess stock market return predictability related to labor market conditions.

\section{Calibrated Models}

Here we present our four calibrated models. The first two are the standard case with and without asymmetric adjustment costs. Asymmetric adjustment costs are necessary in order to generate return predictability.

Next we present the model with labor frictions, but no adjustment costs. This model matches the stylized labor market facts relatively well, but does not generate any predictability in equity returns.

Finally, we present a model with asymmetric adjustment costs to the labor market as well as for investments. This model generates predictability related to fluctuations in both the aggregate investment to capital ratio as well as the aggregate employment / hours worked.

Table 3 shows the parameter values for the models. The capital share, $\alpha$, depreciation, $\delta$, mean technology growth rate, $\mu$, are given standard values. Further, we choose a relatively 


\section{Table 3}

\section{Calibration (Quarterly)}

Table 3: Calibrated values of parameters across models. The upper panel gives parameter values that are constant across models, while the lower panel gives parameter values that differ across models. M1 is the benchmark model wih no labor market frictions and symmetric capital adjustment costs. M2 is the model with no labor market frictions, but assymmetric capital adjustment costs. M3 is the model with sticky wages, but no adjustment costs to either capital or labor. Finally, M4 is the model with sticky wages, as well as assymetric adjustment costs to both capital and labor.

Parameters that are the same across models

\begin{tabular}{|c|c|c|c|c|c|}
\hline Parameter & Description & \multicolumn{4}{|c|}{ Value } \\
\hline$\alpha$ & Capital share in production function & \multicolumn{4}{|c|}{0.34} \\
\hline$\delta$ & Depreciation rate of capital & \multicolumn{4}{|c|}{0.02} \\
\hline$\mu$ & Mean technology growth rate & \multicolumn{4}{|c|}{$0.4 \%$} \\
\hline$\beta$ & Time-discounting & \multicolumn{4}{|c|}{0.998} \\
\hline$\psi$ & Elasticity of Intertemporal Substitution & \multicolumn{4}{|c|}{2} \\
\hline$\gamma$ & Coefficient of Risk aversion & \multicolumn{4}{|c|}{5} \\
\hline \multicolumn{6}{|c|}{ Parameters that are different across models } \\
\hline & & "M1 & M2 & 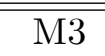 & M4 \\
\hline$a_{k}^{h}$ & Adjustment cost parameter capital increase & 6.8 & 25 & 0 & 25 \\
\hline$a_{k}^{l}$ & Adjustment cost parameter capital decrease & 6.8 & 3 & 0 & 0 \\
\hline$a_{n}^{h}$ & Adjustment cost parameter labor increase & 0 & 0 & 0 & 0 \\
\hline$a_{n}^{l}$ & Adjustment cost parameter labor decrease & 0 & 0 & 0 & 0.4 \\
\hline $\bar{w}$ & Relative wage level & 0.64 & 0.64 & 0.55 & 0.55 \\
\hline$\eta$ & Wage stickiness $(\eta<1)$ & 1 & 1 & 0.9 & 0.9 \\
\hline
\end{tabular}


high elasticity of intertemporal substitution of 2 to maximize the models' ability to match the high volatility of investments. We let the coefficient of risk aversion be 5, which is relatively low. These value for EIS and RRA implies that the representative agent has a preference for early resolution of uncertainty, which is what generates a positive price of risk for shocks to expected consumption growth (long-run risk). The previous variables are kept constant across the models. We vary the amount of adjustment costs to both capital and labor, as well as the amount of wage stickiness, across the models and will comment on the effect of these parameters as we go along. All the models are solved numerically.

Table 4 shows standard unconditional moments from the four models. All models are calibrated to match the volatility of consumption growth and the relative volatility of consumption to output. Matching this relative volatility is important for getting the right amount of long-run risk in the model, as detailed in Kaltenbrunner and Lochstoer (2007). All the models therefore generate about the same amount of short-run and long-run risk (volatility of shocks to realized consumption growth and volatility of expected consumption growth, respectively) and the same maximal price of risk (that is, $\sigma(M) / E(M)$ where $M$ is the stochastic discount factor, as shown by Hansen and Jagannathan, 1992). This, in turn, means that the Sharpe ratio of equities is about the same in all the models and we match this moment to the historical Sharpe ratio of aggregate equity returns.

\section{Labor Market Moments}

The benchmark models, with and without adjustment costs, do not match aggregate labor market moments. In particular, wages are too volatile, hours worked and the labor share (labor income divided by total output) is constant, and wages are too highly (perfectly) correlated with output. In contrast, both the models with sticky wages (with and without adjustment costs) do a significantly better job at matching these moments. As in the data, the labor share is counter-cyclical and about half as volatile as output. This is important for asset pricing moments of the model as it implies that the capital share is pro-cyclical and therefore more risky than in the benchmark models. Further, hours worked and wages are less volatile than output but pro-cyclical, again in line with the data. Thus, the dynamic behavior of the costs of the main factor input in the production function, labor, is significantly better matched with the data in a model that allows for sticky wages.

\section{Investment and Steady-States}

The benchmark models cannot match the high volatility of investment. This fact is related 
Table 4 - Unconditional Moments Across Models

Table 4: This table shows standard annual moments of aggregate quantities and prices for the four models considered in the paper. The models are simulated at a quarterly frequency but all moments are annualized. Notation: $\Delta c$ denotes log consumption growth, a $H P$ superscript means the variable has been detrended using the Hodrick-Prescott filter with standard smoothing parameter equal to $1600, y$ is $\log$ output, $c$ is $\log$ consumption, $i$ is log investment, $w$ is log wage rate, $n$ is $\log$ hours worked, $l s$ is the labor share (a percentage rate), $M$ is the stochastic discount factor, Fraction $L R R$ denotes the fraction of the maximal Sharpe ratio that is due to long-run risk, $S R$ denotes Sharpe ratio, $R_{A}$ is the return to the claim to aggregate consumption, $R_{f}$ is the risk free rate, and $R_{E}$ is the claim to aggregate dividends (the equity claim). ${ }^{*}$ This moment is taken from Bansal, Kiku, and Yaron (2006). ** This moment is taken from Lustig, Van Nieuwerburgh, and Verdelhan (2008).

\begin{tabular}{ccccc}
\hline U.S. & Benchmark & Assymmetric & Labor Model & Labor Model \\
Data & Model & Cap. Adj. Costs & No Adj. Costs & w/Adj. Costs \\
\hline
\end{tabular}

Panel A: Macro Moments

\begin{tabular}{|c|c|c|c|c|c|}
\hline$\sigma(\Delta c)(\%)$ & 2.72 & 2.72 & 2.72 & 2.72 & 2.72 \\
\hline$\sigma\left(c^{H P}\right) / \sigma\left(y^{H P}\right)$ & 0.52 & 0.52 & 0.52 & 0.55 & 0.53 \\
\hline$\sigma\left(i^{H P}\right) / \sigma\left(y^{H P}\right)$ & 3.32 & 1.78 & 1.83 & 2.55 & 3.28 \\
\hline$\sigma\left(w^{H P}\right) / \sigma\left(y^{H P}\right)$ & 0.41 & 1.00 & 1.00 & 0.76 & 0.80 \\
\hline$\sigma\left(n^{H P}\right) / \sigma\left(y^{H P}\right)$ & 0.84 & 0.00 & 0.00 & 0.29 & 0.23 \\
\hline$\sigma\left(l s^{H P}\right) / \sigma\left(y^{H P}\right)$ & 0.50 & 0.00 & 0.00 & 0.52 & 0.52 \\
\hline $\operatorname{Corr}\left(w^{H P}, y^{H P}\right)$ & 0.31 & 1.00 & 1.00 & 0.80 & 0.79 \\
\hline $\operatorname{Corr}\left(n^{H P}, y^{H P}\right)$ & 0.87 & 0.00 & 0.00 & 0.83 & 0.77 \\
\hline $\operatorname{Corr}\left(l s^{H P}, y^{H P}\right)$ & -0.29 & 0.00 & 0.00 & -0.42 & -0.43 \\
\hline$C / Y$ & 0.72 & 0.62 & 0.63 & 0.75 & 0.77 \\
\hline$I / Y$ & 0.28 & 0.38 & 0.37 & 0.25 & 0.23 \\
\hline$D / Y$ & 0.12 & -0.02 & -0.01 & 0.13 & 0.15 \\
\hline
\end{tabular}

Panel B: Asset Pricing Moments

\begin{tabular}{|c|c|c|c|c|c|}
\hline$\sigma(M) / E(M)$ & $n / a$ & 0.37 & 0.36 & 0.32 & 0.37 \\
\hline$S R\left(R_{A}\right)$ & $0.22^{* *}$ & 0.37 & 0.36 & 0.32 & 0.37 \\
\hline$S R\left(R_{E}\right)$ & 0.33 & 0.37 & 0.36 & 0.32 & 0.37 \\
\hline$E\left(R_{f}\right)(\%)$ & 0.86 & 0.48 & 0.48 & 0.33 & 0.62 \\
\hline$\sigma\left(R_{f}\right)(\%)$ & 0.97 & 0.31 & 0.43 & 0.37 & 0.86 \\
\hline$E\left(R_{A}-R_{f}\right)(\%)$ & $2.2^{* *}$ & 1.99 & 1.97 & 1.79 & 1.85 \\
\hline$\sigma\left(R_{A}-R_{f}\right)(\%)$ & $9.8^{* *}$ & 5.25 & 5.14 & 4.62 & 5.03 \\
\hline$E\left(R_{E}-R_{f}\right)(\%)$ & 6.33 & 0.59 & 0.75 & 1.68 & 1.78 \\
\hline$\sigma\left(R_{E}-R_{f}\right)(\%)$ & 19.42 & 1.57 & 2.09 & 4.31 & 4.88 \\
\hline Fraction LRR & $0.6^{*}$ & 0.63 & 0.62 & 0.56 & 0.63 \\
\hline
\end{tabular}


to the high steady state investment to output ratios in these models. The high elasticity of intertemporal substitution generates a high savings demand. Therefore, the level of investment in these economies is too high relative to the empirical counterpart. This feeds into investment volatility which now cannot be very high if we are to match the relative volatility of consumption and output. If the base of which volatility is measured relative to is decreased, however, the same level of fluctuations would be relatively larger. Perhaps the easiest way to see this is by writing $\frac{d Y}{Y}=\frac{d C}{C} \frac{C}{Y}+\frac{d I}{I} \frac{I}{Y}$ : For given levels of output and consumption growth volatilities, the percentage fluctuations in investment must be lower when the investment to output ratio is higher. This is a significant short-coming of the benchmark models. The models with labor frictions, however, match the empirical value for the average investment to output ratio and therefore also better match the investment volatility. In fact, the model with labor friction and adjustment costs generates the right amount of investment volatility.

\section{Asset Pricing Moments}

As mentioned earlier, all the models can match the empirical value for the Sharpe ratio of the equity claim (0.33). Consumption volatility is $2.72 \%$ and the risk aversion coefficient is 5. With power utility preferences, this would result in a Sharpe ratio of 0.13 . However, due to endogenous consumption-smoothing, there is substantial long-run consumption risk in this economy, as explained in the previous section. In fact, about $60 \%$ of the equity premium across the models are due to exposure to long-run consumption risk. The average excess return to the aggregate wealth portfolio is about $2 \%$ p.a. across all models, which is very close to the value estimated by Lustig, Van Nieuwerburgh, and Verdelhan (2008). Furthermore, both the level and volatility of the real risk free rate is matched well by all models, although somewhat better by the labor friction models. Matching these moments also implies that the stochastic discount factor is in line with the data.

The annual equity risk premium for the unlevered firm is about $0.6 \%-0.7 \%$ in the benchmark models. Even this magnitude is high for frictionless RBC models, but is in this case due to capital adjustment costs. The issue is really to generate enough return volatility. While adding leverage will help somewhat, we are an order of magnitude away from the empirical value. The risk premium for the models with labor frictions is more than twice that of the benchmark models at $1.7 \%-1.8 \%$. This is not due to increased adjustment costs, as one may think. The model without any adjustment costs (Model 3) has a risk premium of $1.7 \%$. This is due to the fact that sticky wages related to the aggregate capital stock 
make investing less desirable for the firm as it also increases the wage level. This leads to a lower average investment to output ratio, which in turn also means a higher dividends to output ratio. In the benchmark model this was in fact negative(!), while the models with labor market frictions has this level more in line with the data. The higher level of dividends make dividends more pro-cyclical which is what increases the equity premium. The equity premium is still substantially below its empirical value, but we will in a later section consider the amount of leverage we should add to this claim to make it closer to the public equity claim we actually have historical data for.

In sum, the models with labor market frictions do reasonable well at matching both aggregate unconditional quantities and prices. Next we turn to conditional moments of equity returns.

\subsection{Predictability}

There is a substantial literature documenting that aggregate excess equity returns are predictable (see, e.g., Lettau and Ludvigson, 2001). In context of the models consider in this paper, this implies that the equity risk premium is time-varying. As shown in Kaltenbrunner and Lochstoer (2006) and Campanale, Castro, and Clementi (2007), the standard productionbased model with homoskedastic technology shocks and (relatively) symmetric adjustment costs does not generate economically significant time-variation in expected excess returns. Here we show that the models with asymmetric adjustment costs to capital and labor, on the other hand, are able to do this. Table 5 shows that asymmetric adjustment costs generates long-horizon predictability consistent with what we find in the data. Note the large smallsample bias in the $R^{2}$ 's and the regression coefficient even for the models with no economic predictability.

Table 6 shows that the model with labor frictions generates predictability related to labor market fluctuations in hours worked. We documented earlier that wages are less sensitive to labor productivity in recessions and the final model with labor frictions incorporates this intuition and shows that it leads to quantitatively interesting effects. This is consist with the importance ascribed to fluctuations in labor income as discussed in Lettau and Ludvigson (2001) and Santos and Veronesi (2006).

In sum, asymmetric adjustment costs are necessary in this model to generate time-varying expected equity returns. They do so mainly by increasing price volatility in recessions. 


\section{Table 5 - Excess return predictability: Consumption-Wealth Ratio}

Table 5: The small-sample regressions in the left panels are performed using simulated data from each of the models. The excess return forecasting horizons are 1 quarter, 1 year and 4 years. The data is overlapping at a quarterly frequency and each sample is 240 quarters long (60 years). The reported regression coefficients and $t$-statistics are the sample averages from running 500 such regressions. The $t$-statistics reported in parantheses are Newey-West with a lag equal to the number of overlapping periods. The right panels reports population values for the regression coefficients and the $R^{2}$ 's. One, two, or three asterices denote significance at the ten, five, or one percent level or better, respectively.

\begin{tabular}{|c|c|c|c|c|c|c|c|}
\hline \multicolumn{8}{|c|}{$R_{E, t, t+q}-R_{f, t, t+q}=\beta_{0}+\beta_{1} \ln \left(C_{t} / A_{t}\right)+\varepsilon_{t, t+q}$} \\
\hline $\begin{array}{c}\text { Horizon } \\
\text { (quarters) } q\end{array}$ & $\begin{array}{c}\beta_{0} \\
(t-s t a t)\end{array}$ & $\begin{array}{c}\beta_{1} \\
(t-s t a t)\end{array}$ & $R^{2}$ & $\begin{array}{c}\text { Horizon } \\
q\end{array}$ & $\beta_{0}$ & $\beta_{1}$ & $R^{2}$ \\
\hline
\end{tabular}

Panel A: Model 1 (Symmetric Capital Adjustment costs)

$\begin{array}{cccccccc}1 & 0.069 & 0.010 & 0.2 \% & 1 & -0.008 & -0.002 & 0.0 \% \\ 4 & (0.700) & (0.679) & & & & & \\ & 0.267 & 0.040 & 1.8 \% & 4 & -0.031 & -0.006 & 0.0 \% \\ 16 & (0.939) & (0.912) & & & & & \\ & 0.974 & 0.147 & 7.4 \% & 16 & -0.096 & -0.019 & 0.1 \% \\ & (1.342) & (1.307) & & & & & \end{array}$

Panel B: Model 2 (Asymmetric Capital Adjustment Costs)

$\begin{array}{cccccccc}1 & 0.187^{*} & 0.029^{*} & 1.3 \% & 1 & 0.096 & 0.014 & 0.6 \% \\ 4 & (1.803) & (1.780) & & & & & \\ & 0.714^{* *} & 0.109^{* *} & 6.1 \% & 4 & 0.369 & 0.056 & 2.1 \% \\ 16 & (2.370) & (2.350) & & & & & \\ & 2.403^{* * *} & 0.367^{* * *} & 21.6 \% & 16 & 1.287 & 0.194 & 7.1 \% \\ & (3.142) & (3.105) & & & & & \end{array}$

Panel C: Sticky Wages (no adjustment costs)

$\begin{array}{cccccccc}1 & 0.258 & 0.039 & 0.2 \% & 1 & 0.056 & 0.008 & 0.0 \% \\ 4 & (0.779) & (0.762) & & & & & \\ & 0.981 & 0.150 & 1.9 \% & 4 & 0.207 & 0.029 & 0.1 \% \\ & (1.048) & (1.026) & & & & & \\ & 3.312 & 0.503 & 7.0 \% & 16 & 0.682 & 0.095 & 0.2 \% \\ & (1.526) & (1.411) & & & & & \end{array}$

Panel D: Sticky Wages (with asymmetric adjustment costs)

\begin{tabular}{|c|c|c|c|c|c|c|c|}
\hline 1 & $\begin{array}{c}0.421 \\
(1.631)\end{array}$ & $\begin{array}{l}0.083^{*} \\
(1.705)\end{array}$ & $0.8 \%$ & 1 & 0.141 & 0.021 & $0.4 \%$ \\
\hline 4 & $\begin{array}{c}1.431^{* *} \\
(2.341)\end{array}$ & $\begin{array}{c}0.278^{* *} \\
(2.211)\end{array}$ & $5.1 \%$ & 4 & 0.5204 & 0.078 & $1.1 \%$ \\
\hline 16 & $\begin{array}{l}4.138^{* *} \\
(-2.941)\end{array}$ & $\begin{array}{c}0.834^{* *} \\
(2.332)\end{array}$ & $17.4 \%$ & 16 & 1.559 & 0.232 & $3.6 \%$ \\
\hline
\end{tabular}




\section{Table 6 - Excess return predictability: Hours}

Table 6: The small-sample regressions in the left panels are performed using simulated data from each of the models. The excess return forecasting horizons are 1 quarter, 1 year and 4 years. The data is overlapping at a quarterly frequency and each sample is 240 quarters long (60 years). The reported regression coefficients and $t$-statistics are the sample averages from running 500 such regressions. The $t$-statistics reported in parantheses are Newey-West with a lag equal to the number of overlapping periods. The right panels reports population values for the regression coefficients and the $R^{2}$ 's. One, two, or three asterices denote significance at the ten, five, or one percent level or better, respectively.

$$
R_{E, t, t+q}-R_{f, t, t+q}=\beta_{0}+\beta_{1} N_{t}+\varepsilon_{t, t+q}
$$

\begin{tabular}{|c|c|c|c|}
\hline \multicolumn{4}{|c|}{ Small-sample } \\
\hline $\begin{array}{c}\text { Horizon } \\
\text { (quarters) } q\end{array}$ & $\begin{array}{c}\beta_{0} \\
(t-s t a t)\end{array}$ & $\begin{array}{c}\beta_{1} \\
(t-\text { stat })\end{array}$ & $R^{2}$ \\
\hline
\end{tabular}

\begin{tabular}{cccc}
\multicolumn{3}{c}{ Population } \\
\hline $\begin{array}{c}\text { Horizon } \\
q\end{array}$ & $\beta_{0}$ & $\beta_{1}$ & $R^{2}$ \\
\hline
\end{tabular}

Panel A: Sticky Wages (no adjustment costs)

$\begin{array}{lccccccc}1 & 0.063 & -0.072 & 0.2 \% & 1 & 0.015 & -0.013 & 0.0 \% \\ 4 & (0.871) & (-0.798) & & & & & \\ & 0.242 & -0.276 & 2.0 \% & 4 & 0.059 & -0.050 & 0.1 \% \\ 16 & (1.156) & (-1.057) & & & & & \\ & 0.797 & -0.895 & 7.4 \% & 16 & 0.212 & -0.172 & 0.2 \% \\ & (1.526) & (-1.384) & & & & & \end{array}$

Panel B: Sticky Wages (with adjustment costs)

\begin{tabular}{|c|c|c|c|c|c|c|c|}
\hline 1 & $\begin{array}{l}0.134 \\
(1.781)\end{array}$ & $\begin{array}{l}-0.199 \\
(-1.941)\end{array}$ & $1.1 \%$ & 1 & 0.038 & -0.042 & $0.2 \%$ \\
\hline 4 & $\begin{array}{l}0.491 \\
(2.541)\end{array}$ & $\begin{array}{c}-0.631^{* * *} \\
(-2.451)\end{array}$ & $6.5 \%$ & 4 & 0.146 & -0.160 & $1.1 \%$ \\
\hline 16 & $\begin{array}{c}1.321^{* * *} \\
(3.115)\end{array}$ & $\begin{array}{c}-1.831^{* * *} \\
(-2.631)\end{array}$ & $18.1 \%$ & 16 & 0.475 & -0.503 & $3.3 \%$ \\
\hline
\end{tabular}




\section{Which Moment To Match?}

The representative firm in the models analyzed in this paper represents the entire productive sector. That is private equity, and property, as well as the public equity market. In fact, the public equity market represents only a relatively small fraction of private sector production (Heaton and Lucas, 2000). Furthermore, the average firm in the stock market index is financially levered. Thus, it is not clear that the average stock market return and volatility are the right numbers for us to match with our representative firm.

One way to attack this issue is to consider the aggregate dividends as reported by NIPA versus the aggregate dividends of the publicly traded firms. Bansal and Yaron (2004) report that the volatility of annual real dividend growth is $11.5 \%$. The volatility of aggregate real annual dividend growth over the same period (1929 - 1998) as reported by NIPA, however, is only $6.3 \%$. This implies a "leverage ratio" of 1.83 . This is a higher leverage ratio than that we obtain if we consider only financial leverage (about 1.33). With this higher leverage ratio, we obtain an equity risk premium of more than $3 \%$ for the models with labor market frictions. If one desires to match the level of the equity premium, but not the Sharpe ratio of equities, one can increase the coefficient of risk aversion, $\gamma$, as changing this parameter does not significantly affect quantity dynamics in this model (see also Tallarini (2000), Kaltenbrunner and Lochstoer (2006), and Croce (2008)). Table 7 gives the levered equity risk premium and volatility for both $\gamma=5$ and $\gamma=10$. With a risk aversion parameter of 10 , the models with labor market frictions are able to match the historical risk premium on public equities $(6.3 \%)$. However, the Sharpe ratio is in this case too high as the return volatility is still about half of its historical value.

\section{Conclusion}

We have shown that incorporating labor market frictions that allows a standard productionbased model to match aggregate labor market facts, significantly increases the risk of the equity claim. The sticky labor costs, due to both sticky wages and labor factor adjustment costs, generates operational leverage for the firm. In particular, investment becomes less attractive as these costs prevent the firm from maximally exploiting the capital stock relative to the benchmark case where wages are equal to the marginal labor productivity. Thus, investment is less pro-cyclical and dividends is more pro-cyclical and therefore more risky.

We have empirically documented that wages respond less to changes in labor productivity 


\section{Table 7 - The Levered Equity Claim}

Table 7: This table shows annual moments of aggregate prices for the four models considered in the paper. The models are simulated at a quarterly frequency but all moments are annualized. Notation: $\gamma$ denotes the coefficient of risk aversion, $S R$ denotes Sharpe ratio, $R_{f}$ is the risk free rate, and $R_{E}$ is the levered claim to aggregate dividends (the equity claim with a leverage ratio of 1.83 applied).

\begin{tabular}{lccccc}
\hline & $\begin{array}{c}\text { U.S. } \\
\text { Data }\end{array}$ & $\begin{array}{c}\text { Benchmark } \\
\text { Model }\end{array}$ & $\begin{array}{c}\text { Assymmetric } \\
\text { Cap. Adj. Costs }\end{array}$ & $\begin{array}{c}\text { Labor Model } \\
\text { No Adj. Costs }\end{array}$ & $\begin{array}{c}\text { Labor Model } \\
\text { w/ Adj. Costs }\end{array}$ \\
\hline & & & & & \\
Panel A: $\gamma=5$ & & & & & \\
$S R\left(R_{E}\right)$ & 0.33 & 0.37 & 0.36 & 0.32 & 0.37 \\
$E\left(R_{E}-R_{f}\right)(\%)$ & 6.33 & 1.08 & 1.37 & 7.07 & 3.25 \\
$\sigma\left(R_{E}-R_{f}\right)(\%)$ & 19.42 & 2.87 & 3.82 & & \\
& & & & & \\
Panel B: $\gamma=10$ & & & & 0.72 & 0.74 \\
$S R\left(R_{E}\right)$ & 0.33 & 0.72 & 0.74 & 6.06 & 6.69 \\
$E\left(R_{E}-R_{f}\right)(\%)$ & 6.33 & 2.71 & 3.36 & 8.36 & 9.09 \\
$\sigma\left(R_{E}-R_{f}\right)(\%)$ & 19.42 & 3.75 & 4.53 & & \\
\hline
\end{tabular}

in recessions, a fact that we replicate in our model by allowing for asymmetric adjustment costs to labor. This generates predictability in equity returns related to labor market fluctuations, which has been shown to be important for explaining asset prices (e.g., Lettau and Ludvigson, 2001, and Santos and Veronesi, 2005).

In future work, we aim to investigate in more detail the so-called composition effect generated by fluctuations in human capital versus financial wealth (Duffee, 2005, and Santos and Veronesi, 2005) within this class of models. This requires multiple shocks, which is a natural extension. Further, we aim to investigate how the externalities created by sticky wages affects the decentralized competitive equilibrium differently from the social planner problem which we have solved in this paper. A separation of the investment and consumption decision can potentially increase investment volatility, which it is otherwise difficult for the models to fully match. Higher investment volatility would also allow for higher capital adjustment costs, which would help increase equity return volatility.

\section{References}

Abel, Andrew B. "Asset Prices under Habit Formation and Catching Up with the Joneses." American Economic Review, May 1990, 80(2), pp. 38-42. 
Backus, David K. and Zin, Stanley E. "Reverse Engineering the Yield Curve." NBER Working Paper No. 4676, 1994.

Bansal, Ravi; Kiku D. and Yaron, Amir. "Risks for the Long Run: Estimation and Inference." Working paper, Duke University, 2006.

Bansal, Ravi and Yaron, Amir. "Risks for the Long Run: A Potential Resolution of Asset Pricing Puzzles." Journal of Finance, August 2004, 59(4), pp. 1481-1509.

Bansal, Ravi; Dittmar, Robert F. and Lundblad, Christian T. "Consumption, Dividends, and the Cross-Section of Equity Returns." Journal of Finance, 2004, 60, pp. 1639-1672.

Barsky, Robert and DeLong, Bradford J. "Why Does the Stock Market Fluctuate?" Quarterly Journal of Economics, May 1993, 108(2), pp. 291-312.

Boldrin, Michele; Christiano, Lawrence J. and Fisher, Jones D.M. "Habit Persistence, Asset Returns, and the Business Cycle." American Economic Review, March 2001, 91(1), pp. 149-166.

Campbell, John Y. "Asset Prices, Consumption, and the Business Cycle." Handbook of Macroeconomics, 1999, Volume 1, Chapter 19, pp. 1231-1303.

Campbell, John Y. "Inspecting the Mechanism. An Analytical Approach to the Stochastic Growth Model." Journal of Monetary Economics, 1994, 33, pp. 463-506.

Cochrane, John. "Financial Markets and the Real Economy." Foundations and Trends in Finance, 2005, 1(1), pp. 1-101.

Cochrane, John. "Asset Pricing." Princeton University Press, 2001.

Cochrane, John and Hansen, Lars. "Asset Pricing Explorations for Macroeconomics" In: Olivier Blanchard and Stanley Fisher (Eds.), NBER Macroeconomics Annual, 1992, pp. 115-165.

Cooley, Thomas F. and Prescott, Edward C. "Economic Growth and Business Cycles." In: Thomas Cooley F. (Ed.), Frontiers of Business Cycle Research. Princeton University Press, Princeton, NJ, 1995, pp. 1-37.

Croce, Mariano M. "A New Hope for Production-Based Asset Pricing." Working Paper, University of North Carolina, 2008.

Den Haan, Wouter J. "The Term Structure of Interest Rates in Real and Monetary Economics." Journal of Economic Dynamics and Control, 1995, 19(5/6), pp. 910-940.

Den Haan, Wouter J. and Kaltenbrunner, Georg. "Anticipated Growth and Business Cycles in Matching Models." Working Paper, 2006.

Den Haan, Wouter J.; Ramey, Garey and Watson, Joel. "Job Destruction and 
Propagation of Shocks." American Economic Review, June 2000, 90(3), pp. 482-498.

Duffie, Darrell and Epstein, Larry G. "Stochastic Differential Utility." Econometrica, 1992, 60, pp. 353-394.

Epstein, Larry G. and Zin, Stanley E. "Substitution, Risk Aversion, and the Temporal Behavior of Consumption and Asset Returns: An Empirical Analysis." Journal of Political Economy, 1991, 99(2), pp. 263-286.

Epstein, Larry G. and Zin, Stanley E. "Substitution, Risk Aversion, and the Temporal Behavior of Consumption and Asset Returns: A Theoretical Framework." Econometrica, 1989, 57(4), pp. 937-969.

Friedman, Milton. "A Theory of the Consumption Function." NBER, Princeton, 1957.

Hall, Robert E. "Stochastic Implications of the Life Cycle-Permanent Income Hypothesis: Theory and Evidence." Journal of Political Economy, December 1978, 86(6), pp. 971-987.

Hall, Robert E. "Employment Fluctuations with Equilibrium Wage Stickiness." American Economic Review, March 2005, 95(1), pp. 50-65.

Hall, Robert E. "Sources and Mechanisms of Cyclical Fluctuations in the Labor Market." Working Paper, Stanford University, 2008.

Hamilton, James D. "Time Series Analysis." Princeton University Press, 1994.

Hansen, Lars Peter; Heaton, John C. and Li, Nan. "Consumption Strikes Back?: Measuring Long Run Risk." Working Paper, 2005.

Harvey, Andrew C. and Shepard, Neil G. "On the Probability of Estimating a Deterministic Component in the Local Level Model." Journal of Time Series Analysis, 1990, 11, pp. 339-347.

Hodrick, Robert J. "Dividend Yields and Expected Stock Returns: Alternative Procedures for Inference and Measurement." Review of Financial Studies, 1992, 5(3), pp. 357-386. Hornstein, Andreas; Krusell, Per and Violante, Giovanni L. "Unemployment and Vacancy Fluctuations in the Matching Model: Inspecting the Mechanism." Economic Quarterly (Federal Reserve Bank of Richmond), Summer 2005, 91(3), pp. 19-51.

Jermann, Urban J. "Asset Pricing in Production Economies." Journal of Monetary Economics, April 1998, 41(2), pp. 257-275.

Kaltenbrunner, Georg. "Asset Pricing in Production Economies - A Matching Model." Working Paper, London Business School, 2006.

Kaltenbrunner, Georg and Lars Lochstoer. "Long-Run Risk through Consumption Smoothing" Working Paper, London Business School, 2006.

Kydland, Finn E. and Prescott, Edward C. "Time to Build and Aggregate Fluctua- 
tions." Econometrica, November 1982, 50(6), pp. 1345-1370.

Lettau, Martin and Sydney Ludvigson. "Consumption, Aggregate Wealth, and Expected Stock Returns" Journal of Finance, June 2001, pp. 815-849.

Lettau, Martin and Uhlig, Harald. "Can Habit Formation be Reconciled with Business Cycle Facts?" Review of Economic Dynamics, January 2000, 3(1), pp. 79-99.

Long, John B. and Plosser, Charles I. "Real Business Cycles." Journal of Political Economy, February 1983, 91, pp. 39-69.

Lucas, Robert E. "Asset Prices in an Exchange Economy." Econometrica, November 1978, 46(6), pp. 1429-1445.

Lustig, Hanno, Stijn Van Nieuwerburgh, and Adrian Verdelhan. "The ConsumptionWealth Ratio." Working paper, Boston University, New York University, and University of California, Los Angeles 2008.

Malloy, Christopher; Moskowitz, Tobias J. and Vissing-Jorgensen, Annette. "Long-Run Stockholder Consumption Risk and Asset Returns." Working Paper, 2005.

Mehra, Rajnish and Prescott, Edward C. "The Equity Premium: A Puzzle." Journal of Monetary Economics, March 1985, 15, pp. 145-161.

Mortensen, Dale T. and Pissarides, Christopher A. "Job Creation and Job Destruction in the Theory of Unemployment." Review of Economic Studies, July 1994, 61(3), pp. 269-300.

Panageas, Stavros and Yu, Jianfeng. "Technological Growth, Asset Pricing, and Consumption Risk over Long Horizons." Wharton Working Paper, 2005.

Parker, Jonathan A. and Julliard, Christian. "Consumption Risk and the Cross Section of Expected Returns." Journal of Political Economy, 2005, 115(1), pp. 185-222.

Prescott, Edward C. "Theory Ahead of Business Cycle Measurement." Carnegie-Rochester Conference Series on Public Policy, 1986, 25, pp. 11-66.

Restoy, Fernando and Rockinger, Michael. "On Stock Market Returns and Returns on Investment." Journal of Finance, June 1994, 49(2), pp. 543-556.

Rouwenhorst, Geert K. "Asset Pricing Implications of Equilibrium Business Cycle Models." In: Thomas Cooley F. (Ed.), Frontiers of Business Cycle Research. Princeton University Press, Princeton, NJ, 1995, pp. 294-329.

Rubinstein, Mark. "The Valuation of Uncertain Income Streams and the Pricing of Options." Bell Journal of Economics and Management Science, 1976, 7(2), pp. 407-425.

Santos, Tano and Pietro Veronesi. "Labor Income and Predictable Stock Returns." Review of Financial Studies, 2006, 19(1), pp. 1-44. 
Shanken, Jay. "On the Estimation of Beta-Pricing Models." Review of Financial Studies, 1992, 5(1), pp. 1-33.

Shimer, Robert. "The Cyclical Behavior of Equilibrium Unemployment and Vacancies." American Economic Review, March 2005, 95(1), pp. 25-49.

Tallarini, Thomas D. Jr. "Risk-Sensitive Real Business Cycles." Journal of Monetary Economics, June 2000, 45(3), pp. 507-532.

Uhlig, Harald. "Macroeconomics and Asset Markets: Some Mutual Implications." Working Paper, 2004.

Valkanov, R. "Long Horizon Regressions: Theoretical Results and Applications", Journal of Financial Economics, 68, 2003, 201-232

Weil, Philippe. "The Equity Premium Puzzle and the Risk-free Rate Puzzle." Journal of Monetary Economics, November 1989, 24, pp. 401-421.

Yogo, Motohiro. "A Consumption-Based Explanation of Expected Stock Returns." Journal of Finance, April 2006, 61(2), forthcoming.

Zhang, Lu. "The Value Premium." Journal of Finance, February 2005a, 60(1), pp. 67-103.

Zhang, Lu. "Anomalies." Working Paper, 2005b. 


\section{Appendix}

\subsection{Benchmark Model—Scaled Variables}

It is often convenient to work with scaled variables, denoted by a $\hat{:}$

$$
\begin{aligned}
\hat{C} & =\frac{C}{Z}, \\
\hat{K} & =\frac{K}{Z}, \\
\hat{I} & =\frac{I}{Z}, \\
\hat{J} & =(1-\gamma) \frac{J}{Z^{1-\gamma}} .
\end{aligned}
$$

Lower case variables denote $\operatorname{logs}$. Thus, $c=\ln C$ and $\hat{c}=\ln \hat{C}$.

\subsection{Benchmark Model With No Investment Costs-Closed Form Solution}

The capital accumulation equation is

$$
\frac{d K}{d t}=K^{\alpha}(N Z)^{1-\alpha}-C-\delta K
$$

where labor augmenting technological progress, $Z$, follows a geometric Brownian motion

$$
\frac{d Z}{Z}=\mu d t+\sigma d w
$$

where $w$ is a standard Brownian motion. The central planner seeks to maximize

$$
J_{0}=E_{0} \int_{0}^{\infty} f\left(C_{t}, J_{t}\right) d t
$$

where

$$
f(c, v)=\frac{\beta}{\rho}\left[c^{\rho}((1-\gamma) v)^{1-\rho /(1-\gamma)}-(1-\gamma) v\right]
$$


subject to to the capital accumulation equation. We introduce scaled variables

$$
\begin{aligned}
\hat{C} & =\frac{C}{Z}, \\
\hat{K} & =\frac{K}{Z}, \\
\hat{J} & =(1-\gamma) \frac{J}{Z^{1-\gamma}} .
\end{aligned}
$$

Hence,

$$
\frac{d \hat{K}}{\hat{K}}=\left(\frac{\hat{K}^{\alpha} N^{1-\alpha}}{\hat{K}}-\frac{\hat{C}}{\hat{K}}-\hat{\delta}\right) d t-\sigma d w,
$$

where $\hat{\delta}=\delta+\mu-\sigma^{2}$. The value function, $J$, satisfies the following Hamilton-Jacobi-Bellman equation:

$$
\begin{aligned}
0= & \sup _{\hat{C}} f\left(\hat{C} Z, \hat{J} \frac{Z^{1-\gamma}}{1-\gamma}\right)+\hat{K} J_{\hat{K}}\left(\frac{\hat{K}^{\alpha} N^{1-\alpha}}{\hat{K}}-\frac{\hat{C}}{\hat{K}}-\hat{\delta}\right)+Z J_{Z} \mu+\frac{1}{2} \hat{K}^{2} J_{\hat{K} \hat{K}} \sigma^{2}-\hat{K} Z J_{\hat{K} Z} \sigma^{2} \\
& +\frac{1}{2} Z^{2} J_{Z Z} \sigma^{2}
\end{aligned}
$$

Since, $J=\hat{J}(\hat{K}) \frac{Z^{1-\gamma}}{1-\gamma}$, the Hamilton-Jacobi-Bellman equation simplifies to give

$$
\begin{aligned}
0= & \sup _{\hat{C}} f\left(\hat{C}, \frac{\hat{J}}{1-\gamma}\right)+\hat{K} \hat{J}^{\prime} \frac{1}{1-\gamma}\left(\frac{\hat{K}^{\alpha} N^{1-\alpha}}{\hat{K}}-\frac{\hat{C}}{\hat{K}}\right)-\hat{K} \hat{J}^{\prime}\left(\frac{\hat{\delta}}{1-\gamma}+\sigma^{2}\right)+\hat{J}\left(\mu-\frac{1}{2} \gamma \sigma^{2}\right), \\
& +\frac{1}{2} \hat{K}^{2} \hat{J}^{\prime \prime} \frac{1}{1-\gamma} \sigma^{2} . \\
0= & \sup _{\hat{C}} \frac{\beta}{\rho}\left(\hat{C}^{\rho} \hat{J}^{1-\frac{\rho}{1-\gamma}}-\hat{J}\right)+\hat{K}^{\prime} \hat{J}^{\prime} \frac{1}{1-\gamma}\left(\frac{\hat{K}^{\alpha} N^{1-\alpha}}{\hat{K}}-\frac{\hat{C}}{\hat{K}}\right)-\hat{K} \hat{J}^{\prime}\left(\frac{\hat{\delta}}{1-\gamma}+\sigma^{2}\right)+\hat{J}\left(\mu-\frac{1}{2} \gamma \sigma^{2}\right), \\
& +\frac{1}{2} \hat{K}^{2} \hat{J}^{\prime \prime} \frac{1}{1-\gamma} \sigma^{2} . \\
0= & \sup \frac{\beta}{\rho}\left(\hat{C}^{\rho} \hat{J}^{-\frac{\rho}{1-\gamma}}-1\right)+\hat{K} \frac{\hat{J}^{\prime}}{\hat{J}} \frac{1}{1-\gamma}\left(\frac{\hat{K}^{\alpha} N^{1-\alpha}}{\hat{K}}-\frac{\hat{C}}{\hat{K}}\right)-\hat{K} \frac{\hat{J}}{\hat{J}}\left(\frac{\hat{\delta}}{1-\gamma}+\sigma^{2}\right)+\left(\mu-\frac{1}{2} \gamma \sigma^{2}\right), \\
& +\frac{1}{2} \hat{K}^{2} \frac{\hat{J}^{\prime \prime}}{\hat{J}} \frac{1}{1-\gamma} \sigma^{2} .
\end{aligned}
$$


Define $\hat{j}=\ln \hat{J}$ and $\hat{k}=\ln \hat{K}$. Hence,

$$
\begin{aligned}
0= & \sup _{\hat{C}} \frac{\beta}{\rho}\left(\hat{C}^{\rho} e^{-\frac{\rho}{1-\gamma} \hat{j}}-1\right)+\hat{j}^{\prime} \frac{1}{1-\gamma}\left(\frac{\hat{K}^{\alpha} N^{1-\alpha}}{\hat{K}}-\frac{\hat{C}}{\hat{K}}\right)-\hat{j}^{\prime}\left(\frac{\hat{\delta}+\frac{1}{2} \sigma^{2}}{1-\gamma}+\sigma^{2}\right)+\left(\mu-\frac{1}{2} \gamma \sigma^{2}\right) \\
& +\frac{1}{2}\left(\hat{j}^{\prime \prime}+\left(\hat{j}^{\prime 2}\right) \frac{1}{1-\gamma} \sigma^{2} .\right.
\end{aligned}
$$

The FOC for consumption is

$$
\beta \hat{C}^{\rho-1} e^{-\frac{\rho}{1-\gamma} \hat{j}}=\hat{j}^{\prime} \frac{1}{1-\gamma} \hat{K}^{-1} .
$$

Substituting the above FOC back into (80) gives a nonlinear ordinary differential equation. We solve this nonlinear ode approximately via expanding around the case where $\alpha=1$, i.e. we find a solution of the form

$$
\hat{j}=\hat{j}_{0}+(\alpha-1) \hat{j}_{1}+\ldots
$$

When $\alpha=1$, the nonlinear ode for $\hat{j}$ can be solved exactly:

$$
\hat{j}_{0}=(1-\gamma)\left[\hat{k}+\frac{1}{1-\psi} \ln \left(\frac{\beta^{\psi}}{(1-\delta)(1-\psi)+\beta \psi}\right)\right] .
$$

Hence, to zeroth order in $\alpha$

$$
\begin{aligned}
J & =\frac{\left(K\left(\frac{\beta^{\psi}}{c_{0}}\right)^{\frac{1}{\psi-1}}\right)^{1-\gamma}}{1-\gamma} \\
C & =c_{0} K
\end{aligned}
$$

where $c_{0}=(1-\delta)(1-\psi)+\beta \psi$. Note that when $\beta<1-\delta, c_{0}>0$ iff $\psi<\frac{1-\delta}{1-\delta-\beta}$. This means that $\psi$ cannot be too much larger than 1.

Expanding the ode for $\hat{j}$ around $\alpha=1$ and substituting in the zeroth order solution gives us a linear ode for $\hat{j}_{1}$. Solving this linear ode subject to the boundary condition that $\hat{j}_{1}$ is finite as $|\hat{k}| \rightarrow \infty$ gives us

$$
\hat{j}_{1}=-\frac{(1-\gamma)}{c_{0}}\left[\frac{\mu-\frac{\sigma^{2}}{2}-(1-\delta)}{c_{0}}+1-(\hat{k}-n)\right],
$$


where $\mu_{\delta}=\mu-\frac{1}{2} \sigma^{2}-(1-\delta)$. Therefore, to first order in $\alpha$

$$
\begin{aligned}
J & =\frac{\left[\left(\frac{\beta^{\psi}}{c_{0}}\right)^{\frac{1}{\psi-1}} e^{\frac{(1-\alpha)\left(\mu_{\delta}+c\right)}{2 c^{2}}}\left(\frac{K}{N Z}\right)^{-\frac{1-\alpha}{c}} K\right]^{1-\gamma}}{1-\gamma}, \\
C & =c_{0}\left(1-\frac{1-\alpha}{c_{0}}\right)^{-\psi} e^{-\frac{(1-\alpha)(\psi-1)}{c_{0}^{2}}\left(\mu_{\delta}+c_{0}\right)}\left(\frac{K}{N Z}\right)^{\frac{(1-\alpha)(\psi-1)}{c_{0}}} K .
\end{aligned}
$$

We can obtain the price of the consumption claim from the value function. To see this note that the representative agent faces an optimal consumption-portfolio choice problem. She seeks to consume a proportion of her wealth and invest the remainder in either the claim to consumption or a locally risk-free bond. Market clearing in the consumption good then implies that $P_{C}=C p_{C}$, where

$$
p_{C}=\frac{1}{c_{0}}\left[\left(1-\frac{1-\alpha}{c_{0}}\right) e^{(1-\alpha) \frac{\mu_{\delta}+c_{0}}{c_{0}^{2}}} E^{\frac{1-\alpha}{(1-\alpha)(\psi-1)+c_{0}}}\right]\left(\frac{C}{N Z}\right)^{-\frac{(1-\alpha)(\psi-1)}{(1-\alpha)(\psi-1)+c_{0}}} .
$$

The capital accumulation equation implies that

$$
\begin{aligned}
\frac{d \hat{K}}{\hat{K}}= & \left(\frac{\hat{K}^{\alpha} N^{1-\alpha}}{\hat{K}}-\frac{\hat{C}}{\hat{K}}-\hat{\delta}\right) d t-\sigma d w \\
= & \left(\left(\frac{N}{\hat{K}}\right)^{1-\alpha}-c_{0}\left(1-\frac{1-\alpha}{c_{0}}\right)^{-\psi} e^{-\frac{(1-\alpha)(\psi-1)}{c_{0}^{2}}\left(\mu_{\delta}+c_{0}\right)}\left(\frac{\hat{K}}{N}\right)^{\frac{(1-\alpha)(\psi-1)}{c_{0}}}-\hat{\delta}\right) d t \\
& -\sigma d w .
\end{aligned}
$$

Hence,

$$
\begin{aligned}
d \hat{k}= & \left(e^{(1-\alpha)(n-\hat{k})}-c_{0}\left(1-\frac{1-\alpha}{c_{0}}\right)^{-\psi} e^{-\frac{(1-\alpha)(\psi-1)}{c_{0}^{2}}\left(\mu_{\delta}+c_{0}\right)} e^{\frac{(1-\alpha)(\psi-1)}{c_{0}}(\hat{k}-n)}-\hat{\delta}-\frac{1}{2} \sigma^{2}\right) d t \\
& -\sigma d w
\end{aligned}
$$

We approximate the above nonlinear stochastic differential equation with a linear stochastic differential equation by using the following linear approximations:

$$
\begin{aligned}
e^{(1-\alpha)(n-\hat{k})} & =1+(1-\alpha)(n-\hat{k})+O\left((1-\alpha)^{2}\right), \\
e^{\frac{(1-\alpha)(\psi-1)}{c_{0}}(\hat{k}-n)} & =1+\frac{(1-\alpha)(\psi-1)}{c_{0}}(\hat{k}-n)+O\left((1-\alpha)^{2}\right) .
\end{aligned}
$$


The above approximations imply that

$$
\begin{aligned}
d \hat{k}= & \left(1+(1-\alpha)(n-\hat{k})-c_{0}\left(1-\frac{1-\alpha}{c_{0}}\right)^{-\psi} e^{-\frac{(1-\alpha)(\psi-1)}{c_{0}^{2}}\left(\mu_{\delta}+c_{0}\right)}\left(1+\frac{(1-\alpha)(\psi-1)}{c_{0}}(\hat{k}-n)\right)-\hat{\delta}-\frac{1}{2} \sigma^{2}\right) d t \\
& -\sigma d w \\
= & {\left[1-c_{0}\left(1-\frac{1-\alpha}{c_{0}}\right)^{-\psi} e^{-\frac{(1-\alpha)(\psi-1)}{c_{0}^{2}}\left(\mu_{\delta}+c_{0}\right)}\right.} \\
& \left.+(1-\alpha)(n-\hat{k})-c_{0}\left(1-\frac{1-\alpha}{c_{0}}\right)^{-\psi} e^{-\frac{(1-\alpha)(\psi-1)}{c_{0}^{2}}\left(\mu_{\delta}+c_{0}\right)} \frac{(1-\alpha)(\psi-1)}{c_{0}}(\hat{k}-n)-\hat{\delta}-\frac{1}{2} \sigma^{2}\right]-\sigma d w,(97) \\
= & {\left[1-c_{0}\left(1-\frac{1-\alpha}{c_{0}}\right)^{-\psi} e^{-\frac{(1-\alpha)(\psi-1)}{c_{0}^{2}}\left(\mu_{\delta}+c_{0}\right)}\right.} \\
& \left.+(1-\alpha)(n-\hat{k})\left(1+c_{0}\left(1-\frac{1-\alpha}{c_{0}}\right)^{-\psi} e^{-\frac{(1-\alpha)(\psi-1)}{c_{0}^{2}}\left(\mu_{\delta}+c_{0}\right)} \frac{(\psi-1)}{c_{0}}\right)-\hat{\delta}-\frac{1}{2} \sigma^{2}\right]-\sigma d w .
\end{aligned}
$$

The above linear stochastic differential equation can be written more concisely as

$$
d \hat{k}=\left(A_{\hat{k}}+B n-B \hat{k}\right) d t-\sigma d w
$$

where

$$
\begin{aligned}
A_{\hat{k}} & =1-c_{0}\left(1-\frac{1-\alpha}{c_{0}}\right)^{-\psi} e^{-\frac{(1-\alpha)(\psi-1)}{c_{0}^{2}}\left(\mu_{\delta}+c_{0}\right)}-\hat{\delta}-\frac{1}{2} \sigma^{2} \\
B & =(1-\alpha)\left(1+c_{0}\left(1-\frac{1-\alpha}{c_{0}}\right)^{-\psi} e^{-\frac{(1-\alpha)(\psi-1)}{c_{0}^{2}}\left(\mu_{\delta}+c_{0}\right)} \frac{(\psi-1)}{c_{0}}\right)
\end{aligned}
$$

The above sde is an Ornstein-Uhlenbeck process and has the following well-known solution

$$
\hat{k}_{s+t}=\frac{A_{\hat{k}}+B n}{B}\left(1-e^{-B s}\right)+e^{-B s} \hat{k}_{t}-\sigma \int_{0}^{s} e^{-B(s-u)} d w_{u}
$$

Therefore,

$$
E_{t}\left[\hat{k}_{s+t}\right]=\frac{A_{\hat{k}}+B n}{B}\left(1-e^{-B s}\right)+e^{-B s} \hat{k}_{t}
$$


Hence,

$$
\begin{aligned}
\operatorname{Var}_{t}\left[\hat{k}_{s+t}\right] & =E_{t}\left[\left(\hat{k}_{s+t}-E_{t}\left[\hat{k}_{s+t}\right]\right)^{2}\right], \\
& =E_{t}\left[\left(\sigma \int_{0}^{s} e^{-B(s-u)} d w_{u}\right)^{2}\right], \\
& =\sigma^{2} E_{t}\left[\left(\int_{0}^{s} e^{-B(s-u)} d w_{u}\right)^{2}\right], \\
& =\sigma^{2} \int_{0}^{s} e^{-2 B(s-u)} d u, \\
& =\frac{\sigma^{2}}{2 B}\left(1-e^{-2 B s}\right)
\end{aligned}
$$

It follows that

$$
\begin{aligned}
\lim _{s \rightarrow \infty} E_{t}\left[\hat{k}_{s+t}\right] & =\frac{A_{\hat{k}}+B n}{B}, \\
\lim _{s \rightarrow \infty} \operatorname{Var}_{t}\left[\hat{k}_{s+t}\right] & =\frac{\sigma^{2}}{2 B}
\end{aligned}
$$

After some algebra, we can also obtain a first order approximation for the evolution of the log of normalized consumption $\hat{c}=\ln \hat{C}$ and hence $c$. Similarly we can obtain a first order approximation for the evolution of the $\log$ of labor income, $l=\ln W N$.

We can show that

$$
\frac{d M}{M}=-r d t-\Theta d z
$$

where

$$
\begin{aligned}
r & =r_{0}+r_{1} \hat{c} \\
\Theta & =\frac{(\gamma-1)(1-\alpha)}{c_{0}} .
\end{aligned}
$$

See mathematica file for details.

\subsection{Full Model}

Proof of Proposition 3. The proof follows Merz and Yashiv (2005). 
The first order conditions for the firm's problem.

$$
\begin{aligned}
0 & =E_{t}\left[M_{t, t+1}\left((1-\alpha) \frac{Y_{t+1}}{N_{t+1}}-g_{N_{t+1}}-W_{t+1}\right)\right]-q_{t}^{N}+E_{t}\left[M_{t, t+1} q_{t+1}^{N}\right] \\
0 & =E_{t}\left[M_{t, t+1}\left(\alpha \frac{Y_{t+1}}{K_{t+1}}-g_{K_{t+1}}\right)\right]-q_{t}^{K}+E_{t}\left[M_{t, t+1} q_{t+1}^{K}(1-\delta)\right] \\
0 & =-1-g_{I_{t}}+q_{t}^{K} \\
0 & =-g_{H_{t}}+q_{t}^{N}
\end{aligned}
$$

which can be rewritten as

$$
\begin{aligned}
0 & =-\left(1+g_{I_{t}}\right) I_{t}+I_{t} q_{t}^{K} \\
0 & =-g_{H_{t}} H_{t}+H_{t} q_{t}^{N} \\
K_{t+1} q_{t}^{K} & =K_{t+1} E_{t}\left[M_{t, t+1}\left(\alpha \frac{Y_{t+1}}{K_{t+1}}-g_{K_{t+1}}+q_{t+1}^{K}(1-\delta)\right)\right] \\
N_{t+1} q_{t}^{N} & =N_{t+1} E_{t}\left[M_{t, t+1}\left((1-\alpha) \frac{Y_{t+1}}{N_{t+1}}-g_{N_{t+1}}-W_{t+1}+q_{t+1}^{N}\right)\right] .
\end{aligned}
$$

From the first reordered FOC it follows that

$$
\begin{aligned}
\left(1+g_{I_{t}}\right) I_{t} & =\left[K_{t+1}-(1-\delta) K_{t}\right] q_{t}^{K} \\
\left(1+g_{I_{t+1}}\right) I_{t+1} & =\left[K_{t+2}-(1-\delta) K_{t+1}\right] q_{t+1}^{K}
\end{aligned}
$$

Therefore

$$
\begin{aligned}
E_{t}\left[M_{t, t+1}\left(1+g_{I_{t+1}}\right) I_{t+1}\right] & =E_{t}\left[M_{t, t+1}\left[K_{t+2}-(1-\delta) K_{t+1}\right] q_{t+1}^{K}\right] \\
E_{t}\left[M_{t, t+1}(1-\delta) K_{t+1} Q_{t+1}^{K}\right] & =E_{t}\left[M_{t, t+1}\left(K_{t+2} Q_{t+1}^{K}-\left(1+g_{I_{t+1}}\right) I_{t+1}\right)\right]
\end{aligned}
$$

From (120) it follows that

$$
E_{t}\left[M_{t, t+1}(1-\delta) Q_{t+1}^{K} K_{t+1}\right]=K_{t+1} Q_{t}^{K}-K_{t+1} E_{t}\left[M_{t, t+1}\left(\alpha \frac{Y_{t+1}}{K_{t+1}}-g_{K_{t+1}}\right)\right]
$$

Hence,

$$
E_{t}\left[M_{t, t+1}\left(K_{t+2} Q_{t+1}^{K}-\left(1+g_{I_{t+1}}\right) I_{t+1}\right)\right]=K_{t+1} Q_{t}^{K}-K_{t+1} E_{t}\left[M_{t, t+1}\left(\alpha \frac{Y_{t+1}}{K_{t+1}}-g_{K_{t+1}}\right)\right]
$$

which implies that

$$
K_{t+1} Q_{t}^{K}-E_{t}\left[M_{t, t+1} K_{t+2} Q_{t+1}^{K}\right]=E_{t}\left[M_{t, t+1}\left\{K_{t+1}\left(F_{K_{t+1}}-g_{K_{t+1}}\right)-I_{t+1}\left(1+g_{I_{t+1}}\right)\right\}\right],
$$


since $F_{K_{t+1}}=\alpha \frac{Y_{t+1}}{K_{t+1}}$.

We define

$$
C F_{t}^{K}=F_{K_{t}} K_{t}-g_{K_{t}} K_{t}-\left(I_{t}+g_{I_{t}} I_{t}\right) .
$$

The claim to the above cash flow has price $\vartheta_{t}^{K}$, so

$$
\vartheta_{t}^{K}=E_{t}\left[M_{t, t+1}\left(C F_{t}^{K}+\vartheta_{t+1}^{K}\right)\right]
$$

But (128) implies that

$$
K_{t+1} Q_{t+1}^{K}-E_{t}\left[M_{t, t+1} K_{t+2} Q_{t+1}^{K}\right]=E_{t}\left[M_{t, t+1} C F_{t+1}^{K}\right] .
$$

Therefore,

$$
\vartheta_{t}^{K}=K_{t+1} Q_{t}^{K}
$$

We also define the cash flow

$$
C F_{t}^{N}=F_{N_{t}} N_{t}-g_{N_{t}} N_{t}-g_{H_{t}} H_{t}-W_{t} N_{t},
$$

the claim to which has price $\vartheta_{t}^{N}$, given by

$$
\vartheta_{t}^{N}=E_{t}\left[M_{t, t+1}\left(C F_{t}^{N}+\vartheta_{t+1}^{N}\right)\right]
$$

Similarly to (131), we can show that

$$
N_{t+1} Q_{t}^{N}-E_{t}\left[M_{t, t+1} N_{t+2} Q_{t+1}^{N}\right]=E_{t}\left[M_{t, t+1} C F_{t+1}^{N}\right]
$$

which implies that

$$
\vartheta_{t}^{N}=N_{t+1} Q_{t}^{N}
$$

Simple algebra shows that the cash flow

$$
F\left(K_{t}, N_{t}\right)-g_{t}-W_{t} N_{t}-I_{t}
$$

is the sum of $C F_{t}^{K}$ and $C F_{t}^{K}$. Therefore the value of the firm, $P_{D, t}$, is given by

$$
P_{D, t}=K_{t+1} Q_{t}^{K}+N_{t+1} Q_{t}^{N}
$$

